\title{
Exploring the bird mind: A review of episodic memory and metacognition studies of western scrub-jays
}

\author{
ARII WATANABE ${ }^{1)}$
}

\begin{abstract}
The view that episodic memory and metacognition are human-unique abilities has been challenged over the recent decades. While much of the focus of nonhuman studies has been on primates, western scrub-jays contributed extensively towards the understanding of these abilities. Western scrub-jays demonstrate episodic-like memory by remembering what, where, and when they cached food items and by using this information flexibly during recovery to change their behaviour according to the situation. In addition to episodic-like memory, recent studies suggest that these birds are also capable of self-reflection in a form of metacognition. Further investigation of their self-reflective ability may be the critical approach in deepening our understanding of episodic memory in nonhuman animals.
\end{abstract}

Key words : metacognition, episodic memory, avian cognition

Are birds really "birdbrains"? The word reflects the widespread notion that the intellect of birds is below that of other animals (there is also an equivalent word in Japanese "tori-atama"). However, research has been accumulating to show that some bird species have complex cognitive capacities that were previously thought to be unique to humans and closely related primates. In particular, studies on episodic memory of western scrub-jays (Aphelocoma californica) have contributed greatly in changing the views of avian cognition. Here, I review the works on western scrub-jay cognition with focuses on episodic memory and metacognition, another increasingly popular area of comparative cognition due to its links with consciousness.

Perhaps, the impression of "birdbrain"

1) Department of Cognitive and Information Sciences, Graduate School of Humanities, Chiba University

1-33 Yayoi-cho, Inage, Chiba, 263-8522, Japan Corresponding author: ARII WATANABE

E-mail: a.watanabe@chiba-u.jp

J-STAGE Advance Published Date: April 12, 2018. doi: 10.2502/janip.68.1.4 comes from its size. The relationship between brain size and intelligence has been a longdebated issue. The question as to whether absolute or relative brain size is a better predictor of cognitive ability is yet unresolved but recently there is increasing evidence in support for the former. For example, MacLean and colleagues (2014) found that performance on self-control tasks was positively correlated with absolute brain volume. There have been other similar findings that suggest cognitive abilities depend on absolute brain size or number of neurons (Deaner, Isler, Burkart, \& Schaik, 2007; HerculanoHouzel, 2011). Under this rule, birds' light brains, adapted for flight, may appear to be at a disadvantage. However, inter-class comparison should be conducted with caution since the bird brain is structurally different from the mammalian brain (see Jarvis et al., 2005). Although many homologous areas have been discovered in the avian and mammalian brains (Jarvis et al., 2005), Olkowicz et al. (2016) may have found one critical difference between the two. According to their investigation, brains of corvids and parrots accommodate more neurons in a given mass than 
those of mammals. Therefore, smaller brain volume may not necessarily be linked to lower processing power.

Such structural characteristic of the avian brain may be underlining the impressive cognitive capabilities demonstrated by some bird species, such as western scrub-jays. Western scrub-jays are a corvid species found in the Americas including the scrub woodlands on the west coast of North America and parts of Mexico (Sauer et al., 2011). Like some of the other passerine species, western scrub-jays engage in caching behaviour - storing food items for later consumption. Observations under a controlled laboratory environment showed that their memory for caches last for as long as 250 days (Bednekoff, Balda, Kamil, \& Hile, 1997). Interspecies comparisons among passerine birds revealed that species that engage in caching have enhanced spatial memory (Hampton \& Shettleworth, 1996; Krebs, Healy, \& Shettleworth, 1990) and larger hippocampus (Hampton \& Shettleworth, 1996; Krebs, Sherry, Healy, Perry \& Vaccarino, 1989; Sherry, Vaccarino, Buckenham, \& Herz, 1989) compared to non-caching species. The role of hippocampus in spatial memory is evidenced in lesions studies (Morris, 1981; Morris, Garrud, Rawlins, \& O'Keefe, 1982) and in discovery of "place cells" (O'Keefe 1979). For caching birds, it is also known that growth of hippocampus size is dependent on caching experience during development (Clayton \& Krebs, 1994).

While caching is an effective strategy to secure stable food source, it also involves risks of losing the caches as a result of memory failure or them being stolen by another individual. To protect their caches from theft, cachers use various techniques to minimise the possibility of others locating their caches. For example, when making caches in presence of observing conspecifics, cachers show preference to cache in locations behind barriers or in the shade (Dally, Emery, \& Clayton, 2005). Additional observation that cache protection strategies were demonstrated only in cachers who had themselves experienced being in the thief's role (Emery \& Clayton, 2001) suggests that these birds perform some type of experience projection in a way similar to theory of mind in humans. It is due to such evidences of complex cognition that scrub-jays are attracting increasing attention as subjects in various fields of comparative cognition.

Episodic memory is probably the area where studies on scrub-jays have contributed most extensively. Episodic memory refers to the ability to reflect on personal past experiences, and the predominant view was that it is unique to humans (Tulving, 1972; 2005). Under Tulving's (1972) original definition of the term, it was stated that such a reflection of an event is characterised by three elements of that event - what the event was, where it occurred, and when it occurred. Scrub-jays made ideal subjects to study these elements of what, where, and when because they cache a variety of food types in the wild, including acorns, softshelled nuts, invertebrates, and pieces of fruit (Vander Waal, 1990). For a successful retrieval of multiple types of cached items, the cachers need to remember not only the exact locations of the buried items but also what they are and how long they remain edible.

Using sand-filled ice cube trays to recreate the birds' natural caching environment in the laboratory, Clayton and Dickinson (1999a) showed that scrub-jays are capable of remembering which item they had cached at which location. This experiment involved two caching phases and two caching trays (A and $\mathrm{B}$ ). During the early caching phase, the scrub-jays were presented with a bowl of peanuts and partly covered trays with only the left side available for caching. In the later caching phase, the trays were brought back with a bowl of dog kibbles but this time the cover was placed over the left side and only the right side was open for caching. Thus, at the end of the caching phases, the left side of both trays contained peanut caches and the right side of the trays contained kibble caches. After a 3-hour delay, 
WATANABE : Exploring the bird mind: A review of episodic memory and metacognition studies of western scrub-jays

the recovery phase started and one of the trays was returned to the subject with its right (kibble) side open. The recovery phase with the other tray followed, with its left (peanut) side open (the order of recovery was counterbalanced across subjects). Then, half of the subjects were fed peanuts and the other half were fed kibbles until satiation before the two trays, each now containing either peanuts or kibbles only, were returned again in the test phase. Scrub-jays are known for showing the specific-satiety effect, meaning that when they are prefed with one type of food, they choose a different type to feed on (Clayton \& Dickinson, 1999b). This effect predicts those that were fed peanuts will have high motivation to look for kibbles during the test, and vice versa. Because all cached items had been removed from the trays to control for odour cues, the authors used the number of probes (inspections) the birds made into the sand with their bills as a measure of their search pattern. Data from 16 birds showed that the greatest number of inspections was directed to the side of the tray which should have contained the nonprefed food. Such search pattern, which would have been a successful recovery had the caches remained, is only possible if the scrub-jays remembered which type of food item was cached in which tray, and whether items have already been recovered. Therefore, this study shows that scrub-jays use memory for what and where of a caching event and in combination.

As well as remembering what and where of an event, the when element is also important for jays that cache foods that decay after a relatively short time, such as soft-bodied invertebrates. This temporal aspect, in terms of "how long ago?" was investigated in another caching study by Clayton and Dickinson (1998). In this study, the decay rate of food was artificially adjusted by experimenters returning cached wax-moth larvae as they were after a delay of 4 hours but replacing them with decayed larvae after 124 hours. After experiencing such consequences during the training, the birds were given two caching phases, separated by 120 hours. In caching phase one, they were presented with a bowl of either peanuts or larvae and a tray with one side open for caching. The alternative food item and tray side were available in caching phase two. The tray was returned after another 4 hours and, as the experiment above, the number of inspections the birds made into each side of the tray was recorded. Because scrub-jays generally prefer larvae over peanuts, they searched mainly for larvae in the corresponding side of the tray in trials where larvae were cached recently in caching phase two (4 hours ago). However, in trials where larvae were cached in caching phase one (124 hours ago), they switched to searching for peanuts. This behaviour indicates that in addition to remembering what they cached where, they can also remember when items were cached. Using a derived paradigm, similar memory ability was also observed in magpies (Zinkivskay, Nazir, \& Smulders, 2009) and black-capped chickadees (Feeney, Roberts, \& Sherry, 2009).

In addition to memory for what, where, and when, Clayton, Yu, and Dickinson (2003) stress two features that are important for the behavioural criteria of episodic memory structure and flexibility. Structure refers to the bound nature in which the three elements are stored in memory. For the cachers in the above experiment, memory for the three elements would have been useless if they were remembered independently. Even if they remembered that there were two types of food, two sides of the tray, and two caching phases, successful recovery would have been only possible if they remembered the particular combination of information (e.g., larvae, left side, 4 hours ago). A study on pigeons, by Skov-Rackette, Miller, and Shettleworth (2006), clearly illustrates the difference between bound and unbound elements in a memory. Pigeons were given extensive training on answering three types of questions about the sample stimulus. After the sample stimulus was presented, the pigeons were required to either select the 
comparison with the same shape as the sample (what test), select a comparison found in the same location as the sample (where test), or report if the sample was presented 2 or 6 seconds ago by selecting the corresponding symbol (when test). Although the pigeons had some difficulty with the when test, eventually they reached the criteria to proceed to the test phase. The test phase included two-test trials where response to the first test was followed by presentation of another type of test. The critical finding was that their performance on the second test was independent of the performance on the first test. This indicates that although the pigeons were able to remember what, where, and when elements of the sample stimulus, these elements were not stored in a bound form.

Clayton and colleagues (2003) argue that because episodic memory is a form of declarative memory, it should be flexible and its use should not be limited to specific situations. Some evidence of flexibility is found in the study above involving decaying larvae (Clayton \& Dickinson, 1998). In the study, there was actually an additional group of birds that was tested on the same paradigm. For this group, cached larvae were always replaced with fresh ones before they were returned and, thus, the birds did not learn that larvae decay. Unlike the original subjects that avoided searching for larvae after a long delay, these birds searched for the preferred larvae regardless of the delay length. Difference in behaviour of the two groups show that this cache recovery behaviour is flexible enough to cater for learning of a new information, in this case, that larvae decay. Further support is provided by Clayton, Yu, and Dickinson (2003) which demonstrated that updating of knowledge during the retention interval can lead to behavioural change in the recovery phase. The scrub-jays that made caches in three different trays over three days found that when the first tray was returned after three days, the cached crickets had become unpalatable. In the following day, unpalatable crickets were returned with the second tray. When returned with the third tray (now empty for testing) on the following test day, they avoided searching for crickets. In contrast, those that were returned with fresh crickets in the first and second trays still showed preference for searching for crickets. Because all birds still showed preference for crickets after short retention interval of 1 day, devaluation of crickets was not enough to explain this switch in preference at 3-days interval. These results led the authors to conclude that the jays' behaviour at recovery is not due to motivational factors during encoding but to flexible use of acquired information during retention and recovery.

The possibility of episodic memory in western scrub-jays has also been explored through their prospective cognition. Because both episodic memory and future thinking require projection of self into a situation other than the currently experiencing one, some researchers believe that they share a common mechanism (Atance \& O'Neil, 2001). Studies of prospective cognition in western scrub-jays also use paradigms that rely on their caching behaviour. In an experiment by Raby, Alexis, Dickinson, and Clayton (2007), jays were locked into either the "breakfast" compartment, where food was provided in the morning, or the "no-breakfast" compartment, where no food was provided, for the duration of the night. On the test night after learning the consequences of each compartment, they were given food items that they could cache into either compartment. If they have the ability to consider possible future scenarios of the following morning, they should cache more items in the "no-breakfast" compartment than in the "breakfast" compartment. This was exactly what was observed. An additional experiment was conducted to examine if the birds' choice was based on association of hunger with the "no-breakfast" compartment. This time, both compartments provided food in the morning but of different types. Scrub-jays usually prefer to have a variety of food, which means that if they are capable of prospective 
WATANABE : Exploring the bird mind: A review of episodic memory and metacognition studies of western scrub-jays

cognition, they would cache items different from what they expect in that compartment in the following morning. On the other hand, if association was the key factor controlling their choice of location to cache, they would cache the same items that had been provided in the compartment in the previous mornings. Again, the jays behaved as predicted by the prospective account. Unlike some studies of future planning in primates that involve repeated presentation of training or test trials (Mulcahy \& Call, 2006; Naqshbandi \& Roberts, 2006), use of one-trial test in western scrub-jay studies has the advantage of easily ruling out association between their actions and consequences as an explanation for their behaviour.

Despite the accumulating evidence that western scrub-jays can pass the behavioural criteria for episodic memory, the one critical aspect of episodic memory, as proposed by Tulving (2005), that is yet to be demonstrated is autonoetic consciousness. Autonoetic consciousness refers to the self-awareness of remembering past events. Clayton and Dickinson (1998) acknowledge the lack of evidence for or against the phenomenological aspects of episodic memory and coined the term episodic-like memory to describe their findings. In fact, conscious awareness, itself, is one of the greatest questions of comparative cognition. Unlike humans, where selfreport of subjective experiences is possible, testing for any type of awareness in nonverbal subjects is a difficult issue.

Reporting of experiences in nonhuman animals was first studied by Cowey and Stoerig (1995) who, using the paradigm originally designed for human blindsight patients (Weiskrantz, 1986), showed that macaque monkeys with unilateral damage to its visual cortex experience a condition similar to blindsight. They responded to stimuli presented to in their affected half of the visual field by pressing the key to report that they did not see any stimuli and yet they could locate them almost perfectly. Paradigms that provide a behavioural way of self-report open up the possibility of studying subjective experiences in nonverbal subjects. In particular, one type of awareness that has been attracting increased attention in the recent decades is metacognition.

Metacognition is the ability to reflect on one's own thinking or knowledge, and some suggest that it is closely linked to consciousness (Metcalfe \& Kober, 2005; Nelson, 1996). A typical metacognition task involves a basic memory test presented with a behavioural means for the subject to report their lack of memory. An animal with metacognition should use this behavioural means, called the uncertainty response, under conditions where they are uncertain and likely to err. For example, in a study by Hampton (2001), rhesus monkeys were presented with a matching-to-sample task with an option to either accept or decline taking the test on some trials. The option to decline led to a guaranteed-win trial but the delivered reward was of a less value than what could be obtained for correctly answering the test. Consequently, the best strategy would be to accept the test when one is certain and decline the test when one is uncertain. However, such strategy is only possible if one can differentiate its own states of certain and uncertain. Three observations from Hampton's monkeys supported use of this strategy. Firstly, their performance was better when they explicitly accepted taking the test than when they were forced to do so. This shows that when given the choice, they were choosing to accept only when they were confident about their memory. Secondly, they used the decline option effectively in probe trials where no sample was displayed and there was no way of knowing what the correct answer was. Thirdly, their choice of declining the test increased as the retention interval was lengthened. Memory decays with time so their uncertainty should have increased with the length of the retention interval. Other experiments using such a combination of uncertainty response with memory tests provide further support for metacognition in primates (e.g., Fujita, 2009; Neldner, Collier-Baker, \& Nielsen, 2015; 
Smith, Shields, Washburn, 1998; Suda-King 2008; Templer \& Hampton, 2012).

Considering Tulving's emphasis on selfreflective ability, metacognition could be the critical element for the progress of episodic memory research in nonverbal animals. Because western scrub-jays have already passed the behavioural criteria for episodic memory, investigating whether they engage in self-reflection during recollection will show if their episodic-like memory is close to human episodic memory. The first step would be to investigate if scrub-jays show any evidence of metacognition at all. This was the focus of Watanabe and Clayton (2016) who used the foraging task to study if scrub-jays are sensitive to their own knowledge state. Unlike the metacognition studies introduced above that used specifically trained responses as the uncertainty response, the foraging task, originally designed by Call and Carpenter (2001), uses responses that are already in animals' behavioural repertoire. When confronted with one's own uncertainty state, a possible reaction to it would be to look for additional information that may be useful to solve the current problem. For the scrub-jays in Watanabe and Clayton (2016), the problem was to locate where food had been hidden by the experimenter. The birds watched while an experimenter hid a bottle cap containing food in one of two tubes. They could, then, approach the tubes and choose one by entering within certain distance of the further baited end of a tube. Before making their choice, they could look into the closer opening of the tube to check the presence of the bottle cap. If subjects can monitor and control their knowledge during memory retrieval, then they should look into the tubes when they do not know the location of the bait and are likely to err. This prediction was supported in three different experiments.

In the first experiment, the jays looked into the tubes more often when the baiting process was hidden from their view than when they could observe it. In the former condition, there was no way of knowing where the food was hidden and thus their uncertainty level would have been high. In the second experiment, their uncertainty level was manipulated by inserting a delay after the baiting process. Their looking behaviour occurred more frequently in trials with 60 -second delay than those without it. In the third experiment, confusion was induced by moving the food to the alternative tube after the initial baiting. Again, the birds showed more looking behaviour under the condition associated with high uncertainty. The result from the third experiment is especially relevant because it contradicts what is predicted by the response-competition account (Crystal \& Foote, 2011). If the birds' behaviour was controlled by the default response of looking into the tube which was sometimes outweighed by the strong motivation to make a direct choice, the jays would not have shown differential looking behaviour in the two conditions, where the level of motivation should have been equal. In sum, the findings from the foraging study showed that western scrub-jays are capable of differentiating their certain and uncertain states and engage in a possible metacognitive strategy to seek more information to complement their high uncertainty.

Most studies on animal metacognition test subjects' ability to assess their current knowledge state. A weakness of such studies is that it is difficult to deduce whether subjects are assessing their mental state or some physiological or behavioural reaction to it. For example, when faced with a difficult problem, you may not realise that you were finding it difficult until you find yourself frowning or taking time to come to an answer. A way to overcome this issue is to study assessment of future knowledge state. In Roberts et al. (2009), pigeons were initially trained on delayed matching-to-sample task then presented with a choice of either seeing the sample stimulus before the matching test or going directly to the test. Seeing the sample was necessary for answering correctly in the test that was to follow and so if they understood the importance of collecting the 
WATANABE : Exploring the bird mind: A review of episodic memory and metacognition studies of western scrub-jays

required information in preparation for test, they should have chosen to see the sample. Yet, they failed to do so and preferred to take the direct route to the test. Contrastingly, Beran and Smith (2011) showed that rhesus macaques in the same situation chose to see the sample.

To investigate scrub-jays' ability of anticipating their future knowledge state, Watanabe, Grodzinski and Clayton (2014) explored the pattern of study time allocation during an observational spatial memory task. The experimental setup included an observation cage, where the subject was placed, and two smaller compartments, each containing four plastic cups, connected to it. During the training trials, an experimenter placed a piece food in one of the cups and the bird could observe this process using a peephole that connected each compartment to the observation cage. Immediately after the baiting had taken place, the entrance into the compartment was opened and the bird could come in to search for the food. There were two types of compartments. In the forced-choice compartment, three of the four cups were closed with lids and so there was only one possible food location. In the freechoice compartment, all four cups were open so, unless the birds remembered the observed baiting location, the chances of finding food was $25 \%$. After experiencing the consequences of the two compartments, the birds were subjected to test trials where, for the first time, they had to allocate observation time between the two peepholes while both compartments were baited simultaneously. They made more looks and spent more time looking into the free-choice compartment, where information was more important for correct location of food, than into the forcedchoice compartment. This finding parallels that of human metacognition studies where subjects spend longer time studying items that they find more difficult (Dunlosky \& Hertzog, 1998; Metcalfe \& Kornell, 2005). It may be that scrub-jays can not only store appropriate food in anticipation of their own future physiological state (Raby, Alexis,
Dickinson, et al., 2007) but can also seek information in anticipation of their future knowledge state.

Western scrub-jays are the only nonprimate species to date that has shown supportive evidence for both episodic-like memory and metacognition. The next step would be to combine these two types of tasks to test if they can differentiate presence and absence of their episodic-like memory. Exploration of self-reflective memory ability in avian species will help to identify the mechanisms behind how such abilities have developed on distant branches of the evolutionary tree. Considering that both episodic memory and metacognition had been thought as human-unique abilities, data from birds have started questioning what makes human minds so special. Perhaps in the near future, "birdbrain" will become a word of praise rather than insult.

\section{References}

Atance, C. M., \& O’Neill, D. K. 2001 Episodic future thinking. Trends in Cognitive Sciences, 5, 533-539.

Bednekoff, P. A., Balda, R. P., Kamil, A. C., \& Hile, A. G. 1997 Long-term spatial memory in four seed-caching corvid species. Animal Behaviour, 53, 335-341.

Beran, M. J., \& Smith, J. D. 2011 Information seeking by rhesus monkeys (Macaca mulatta) and capuchin monkeys (Cebus apella). Cognition, 120, 90-105.

Call, J., \& Carpenter, M. 2001 Do apes and children know what they have seen? Animal Cognition, 3, 207-220.

Clayton, N. S., \& Dickinson, A. 1998 Episodiclike memory during cache recovery by scrub jays. Nature, 395, 272-274.

Clayton, N. S., \& Dickinson, A. 1999a Memory for the content of caches by scrub jays (Aphelocoma coerulescens). Journal of Experimental Psychology-Animal Behavior Processes, 25, 82-91.

Clayton, N. S., \& Dickinson, A. 1999b Motivational control of caching behaviour in the scrub jay, Aphelocoma coerulescens. Ani- 
mal Behaviour, 57, 435-444.

Clayton, N. S., \& Krebs, J. R. 1994 Hippocampal growth and attrition in birds affected by experience. Proceedings of the National Academy of Sciences of the United States of America, 91, 7410-7414.

Clayton, N. S., Yu, K. S., \& Dickinson, A. 2003 Interacting cache memories: Evidence for flexible memory use by western scrub-jays (Aphelocoma californica). Journal of Experimental Psychology-Animal Behavior Processes, 29, 14-22.

Cowey, A., \& Stoerig, P. 1995 Blindsight in monkeys. Nature, 373, 247-249.

Crystal, J. D., \& Foote, A. L. 2011 Evaluating information-seeking approaches to metacognition. Current Zoology, 57, 531-542.

Dally, J. M., Emery, N. J., \& Clayton, N. S. 2005 Cache protection strategies by western scrub-jays, Aphelocoma californica: implications for social cognition. Animal Behaviour, 70, 1251-1263.

Deaner, R. O., Isler, K., Burkart, J., \& van Schaik, C. 2007 Overall brain size, and not encephalization quotient, best predicts cognitive ability across non-human primates. Brain, Behavior and Evolution, 70, 115-124.

Dunlosky, J., \& Hertzog, C. 1998 Training programs to improve learning in later adulthood: Helping older adults educate themselves. In D. J, Hacker, J. Dunlosky, \& A. C. Graesser (Eds.), Metacognition in educational theory and practice. Mahwah; Erlbaum. Pp.249-275.

Emery, N. J., \& Clayton, N. S. 2001 Effects of experience and social context on prospective caching strategies by scrub jays. Nature, 414, 443-446.

Feeney, M. C., Roberts, W. A., \& Sherry, D. F. 2009 Memory for what, where, and when in the black-capped chickadee (Poecile atricapillus). Animal Cognition, 12, 767777.

Fujita, K. 2009 Metamemory in tufted capuchin monkeys (Cebus apella). Animal Cognition, 12, 575-585.

Hampton, R. R. 2001 Rhesus monkeys know when they remember. Proceedings of the
National Academy of Sciences of the United States of America, 98, 5359-5362.

Hampton, R. R., \& Shettleworth, S. J. 1996 Hippocampus and memory in a foodstoring and in a nonstoring bird species. Behavioral Neuroscience, 110, 946-964.

Herculano-Houzel, S. 2011 Brains matter, bodies maybe not: The case for examining neuron numbers irrespective of body size. Annals of the New York Academy of Sciences, 1225, 191-199.

Jarvis, E. D., Güntürkün, O., Bruce, L., Csillag, A., Karten, H., Kuenzel, W., ... Butler, A. B. 2005 Avian brains and a new understanding of vertebrate brain evolution. Nature Reviews Neuroscience, 6, 151-159.

Krebs, J. R., Healy, S. D., \& Shettleworth, S. J. 1990 Spatial memory of Paridae: Comparison of a storing and a nonstoring species, the coal tit, Parus ater, and the great tit, $P$. major. Animal Behaviour, 39, 1127-1137.

Krebs, J. R., Sherry, D. F., Healy, S. D., Perry, V. H., \& Vaccarino, A. L. 1989 Hippocampal specialization of foodstoring birds. Proceedings of the National Academy of Sciences of the United States of America, 86, 1388-1392.

MacLean, E. L., Hare, B., Nunn, C. L., Addessi, E., Amici, F., Anderson, R. C., ... Zhao, Y. 2014 The evolution of selfcontrol. Proceedings of the National Academy of Sciences, 111, E2140-E2148.

Metcalfe, J., \& Kober, H. 2005 Self-reflective consciousness and the projectable self. In H. S. Terrace \& J. Metcalfe (Eds.), The missing link in cognition: Origins of selfreflective consciousness. New York: Oxford University Press. Pp.57-83.

Metcalfe, J., \& Kornell, N. 2005 A Region of Proximal Learning model of study time allocation. Journal of Memory and Language, 52, 463-477.

Morris, R. G. M. 1981 Spatial localization does not require the presence of local cues. Learning and Motivation, 12, 239260.

Morris, R. G. M., Garrud, P., Rawlins, J. N. 
WATANABE : Exploring the bird mind: A review of episodic memory and metacognition studies of western scrub-jays

P., \& O’Keefe, J. 1982 Place navigation impaired in rats with hippocampal lesions. Nature, 297, 681-683.

Mulcahy, N. J., \& Call, J. 2006 Apes save tools for future use. Science, 312, 10381040.

Naqshbandi, M., \& Roberts, W. A. 2006 Anticipation of future events in squirrel monkeys (Saimiri sciureus) and rats (Rattus norvegicus): tests of the Bischof-Kohler hypothesis. Journal of Comparative Psychology, 120, 345-357.

Neldner, K., Collier-Baker, E., \& Nielsen, M. 2015 Chimpanzees (Pan troglodytes) and human children (Homo sapiens) know when they are ignorant about the location of food. Animal Cognition, 18, 683699.

Nelson, T. O. 1996 Consciousness and metacognition. American Psychologist, 51, 102116.

O'Keefe, J. 1979 A review of hippocampal place cells. Progress in Neurobiology, 13, 419-439.

Olkowicz, S., Kocourek, M., Lučan, R. K., Porteš, M., Fitch, W. T., HerculanoHouzel, S., \& Němec, P. 2016 Birds have primate-like numbers of neurons in the forebrain. Proceedings of the National Academy of Sciences, 113, 7255-7260.

Raby, C. R., Alexis, D. M., Dickinson, A., \& Clayton, N. S. 2007 Planning for the future by western scrub-jays. Nature, 445, 919-921.

Roberts, W. A., Feeney, M. C., McMillan, N., MacPherson, K., Musolino, E., \& Petter, M. 2009 Do Pigeons (Columba livia) Study for a Test? Journal of Experimental Psychology-Animal Behavior Processes, 35, 129-142.

Sauer, J. R., Hines, J. E., Fallon, J. E., Pardieck, K. L., Ziolkowski, D. J., Jr., \& Link, W. A. 2011 The North American Breeding Bird Survey, Results and Analysis 1966-2010. Version 12.07.2011 USGS Patuxent Wildlife Research Center, Laurel, MD.

Sherry, D. F., Vaccarino, A. L., Buckenham, K., \& Herz, R. S. 1989 The hippocampal complex of food-storing birds. Brain, Behavior and Evolution, 34, 308-317.

Skov-Rackette, S. I., Miller, N. Y., \& Shettleworth, S. J. 2006 What-where-when memory in pigeons. Journal of Experimental Psychology-Animal Behavior Processes, 32, 345-358.

Smith, J. D., Shields, W. E., \& Washburn, D. A. 1998 Memory monitoring by animals and humans. Journal of Experimental Psychology-General, 127, 227-250.

Suda-King, C. 2008 Do orangutans (Pongo pygmaeus) know when they do not remember? Animal Cognition, 11, 21-42.

Templer, V. L., \& Hampton, R. R. 2012 Rhesus monkeys (Macaca mulatta) show robust evidence for memory awareness across multiple generalization tests. Ani mal Cognition, 15, 409-419.

Tulving, E. 1972 Episodic and semantic memory. In E. Tulving \& W. Donaldson (Eds.), Organisation of memory. New York: Academic Press. Pp.381-403.

Tulving, E. 2005 Episodic Memory and Autonoesis: Uniquely Human? In H. S. Terrace \& J. Metcalfe (Eds.), The missing link in cognition: Origins of self-reflective consciousness. New York: Oxford University Press. Pp.3-56.

Vander Wall, S. B. 1990 Food Hoarding in Animals. Chicago: University of Chicago Press.

Watanabe, A., \& Clayton, N. S. 2016 Hintseeking behaviour of western scrub-jays in a metacognition task. Animal Cognition, 19, 53-64.

Watanabe, A., Grodzinski, U., \& Clayton, N. S. 2014 Western scrub-jays allocate longer observation time to more valuable information. Animal Cognition, 17, 859867.

Weiskrantz, L. 1986 Blindsight: a case study and implications. Oxford: Claredon Press.

Zinkivskay, A., Nazir, F., \& Smulders, T. V. 2009 What-Where-When memory in magpies (Pica pica). Animal Cognition, 12, 119-125.

(2018. 1. 30 受稿, 2018. 3.6 受理) 